\title{
New approaches for the reliable in vitro assessment of binding affinity based on high-resolution real-time data acquisition of radioligand-receptor binding kinetics
}

Markus Zeilinger ${ }^{1,2}$, Florian Pichler ${ }^{1,2}$, Lukas Nics ${ }^{1}$, Wolfgang Wadsak ${ }^{1,3}$, Helmut Spreitzer ${ }^{4}$, Marcus Hacker ${ }^{1}$ and Markus Mitterhauser ${ }^{1,5,6^{*}}$ (D)

\begin{abstract}
Background: Resolving the kinetic mechanisms of biomolecular interactions have become increasingly important in early-phase drug development. Since traditional in vitro methods belong to dose-dependent assessments, binding kinetics is usually overlooked. The present study aimed at the establishment of two novel experimental approaches for the assessment of binding affinity of both, radiolabelled and non-labelled compounds targeting the $\mathrm{A}_{3} \mathrm{R}$, based on high-resolution real-time data acquisition of radioligand-receptor binding kinetics. A novel timeresolved competition assay was developed and applied to determine the $K_{i}$ of eight different $A_{3} R$ antagonists, using $\mathrm{CHO}-\mathrm{K} 1$ cells stably expressing the $\mathrm{hA}_{3} \mathrm{R}$. In addition, a new kinetic real-time cell-binding approach was established to quantify the rate constants $k_{\text {on }}$ and $k_{\text {off }}$ as well as the dedicated $K_{d}$ of the $A_{3} R$ agonist $\left[{ }^{125}\right.$ l]-AB-MECA. Furthermore, lipophilicity measurements were conducted to control influences due to physicochemical properties of the used compounds.
\end{abstract}

Results: Two novel real-time cell-binding approaches were successfully developed and established. Both experimental procedures were found to visualize the kinetic binding characteristics with high spatial and temporal resolution, resulting in reliable affinity values, which are in good agreement with values previously reported with traditional methods. Taking into account the lipophilicity of the $\mathrm{A}_{3} \mathrm{R}$ antagonists, no influences on the experimental performance and the resulting affinity were investigated.

Conclusions: Both kinetic binding approaches comprise tracer administration and subsequent binding to living cells, expressing the dedicated target protein. Therefore, the experiments resemble better the true in vivo physiological conditions and provide important markers of cellular feedback and biological response.

Keywords: Real-time cell-binding studies, Kinetic competition assay, Binding kinetics, Binding affinity, Cell-based ligand interaction analysis, $A_{3} R$

\footnotetext{
* Correspondence: markus.mitterhauser@meduniwien.ac.at

${ }^{1}$ Department of Biomedical Imaging and Image-guided Therapy, Division of

Nuclear Medicine, Radiopharmacy and Experimental Nuclear Medicine,

Waehringer Guertel 18-20, 1090 Vienna, Austria

${ }^{5}$ Department of Pharmaceutical Technology and Biopharmaceutics,

University of Vienna, Vienna, Austria

Full list of author information is available at the end of the article
} 


\section{Background}

Binding studies on pharmacological targets are undoubtedly an indispensable part in drug development, to determine pharmacokinetic parameters of biomolecular interactions. The reliable in vitro assessment of ligand affinity, as well as the understanding of the binding process itself, provides an important contribution to the concept of selective targeting particular bioactive macromolecules in modern molecular medicine. During earlyphase drug development, typically, such in vitro studies are conducted under closed-system conditions as saturation and competition experiments, which provide quantitative parameters for the extent of compound binding to a target region (e.g. receptor) according to the law of mass action [1]. In a conventional competitive binding experiment, the binding of one fixed concentration of a known radioligand is measured at equilibrium in the presence of a stepwise increasing series of concentrations of a non-labelled ligand. Data thus obtained are used to quantify the half-maximum inhibitory concentration $\left(\mathrm{IC}_{50}\right)$ of the non-labelled ligand [2]. Subsequently, the equilibrium inhibitory constant $\left(K_{i}\right)$ can be calculated using the Cheng-Prusoff transformation [3], which serves as an indirect parameter for target affinity of the non-labelled ligand.

In contrast, the binding at equilibrium of an increasing series of concentrations of a radioligand to a particular target region is measured in a classical saturation experiment in order to quantify the equilibrium dissociation constant $\left(K_{d}\right)$ and the concentration of specific binding sites $\left(B_{\mathrm{Max}}\right)$ for the radioligand [4]. Since both traditional in vitro methods belong to dose-dependent assessments, ligand-receptor binding kinetics is usually overlooked. Resolving the kinetic mechanisms of biomolecular interactions governing ligand association and dissociation has become more and more important to improve the performance of binding experiments. Several lines of research retrospectively suggested that high temporal information about the binding kinetics can assist to avoid systematic bias and potential errors of obtained data under equilibrium and non-equilibrium conditions [5-7]. Furthermore, the validation and interpretation of timeresolved pharmacokinetic data advance the formulation of computational methods to analyse biomolecular interactions of ligands with the receptor alone, or even in combination.

In contrast to in vitro binding studies, in an in vivo setting, the concentration of a dedicated ligand to its target region is no longer constant, but changes over time after administration is often influenced by additional factors other than basic biomolecular ligand-receptor interactions. Therefore, the in vitro measured $K_{d}$ alone is not anymore an informative parameter to characterize complex compound interactions, as well as in vivo effectiveness of small molecule drugs, but rather the in vitro assessment of kinetic parameters such as the association rate constant $\left(k_{\mathrm{on}}\right)$ and the dissociation rate constant $\left(k_{\text {off }}\right)[8,9]$. As a consequence, various experimental procedures have been introduced to address a shift from classical affinity-based assessments to kinetic binding approaches $[5,6,10-16]$. In this context, the usual practice of performing kinetic binding experiments is to measure the binding of one or more concentrations of a radioligand with low nanomolar affinity dedicated to the target at various time points and determine $k_{\text {on }}$ and $k_{\text {off }}$. With both rate constants, $K_{d}$ can be calculated as the ratio of $k_{\text {off }} / k_{\text {on }}$ [12]. However, the currently available experimental techniques for the determination of kinetic binding parameters are time-consuming, laborious and lack the possibility of data acquisition with high temporal resolution. For that reason, the existing methods are prone to errors and reduce the scale of applications in determining biomolecular interactions, as well as hamper the high-throughput screening of important binding properties in early-phase drug discovery $[15,17,18]$.

In the present study, we introduce two experimental approaches for the reliable high-throughput in vitro assessment of binding parameters of both, radiolabelled and non-labelled compounds, based on high-resolution, real-time data acquisition of radioligand-receptor binding kinetics. Herein, we present in competitive real-time cell-binding studies an experimental assay to determine the $\mathrm{IC}_{50}$ out of kinetic data in order to calculate the dedicated $K_{i}$ of a non-labelled ligand. Although previously published work already addressed determination of $k_{\text {on }}$, $k_{\text {off }}, K_{d}, K_{i}$ and $B_{\text {Max }}$ [19-22], in the present kinetic realtime cell-binding studies, we established an alternative experimental design for the assessment of the rate constants $k_{\text {on }}$ and $k_{\text {off. }}$ Therefore, the observed rate constant of the association reaction $\left(k_{\mathrm{ob}}\right)$ is used to calculate these parameters out of different increasing concentrations of radioligand. The technical principle of the experimental procedures is based on an equipment technology called LigandTracer ${ }^{\circ}$ (Ridgeview Instruments $A B$, Uppsala, Sweden), which was successfully established and implemented in a variety of studies dealing with pharmacokinetic aspects [23-26]. This technique comprises the possibility of automated high-resolution real-time quantification of biomolecular interactions by use of repeated differential measurements of bound radioligand on cell surface proteins [23]. As a result, we are capable of following the uptake, retention and dissociation of a radioligand to its dedicated target region directly during the experiment.

In the current study, we used the adenosine $\mathrm{A}_{3}$ receptor $\left(A_{3} R\right)$ as a sample target to validate the suitability of the used system and the experimental approaches. 
Adenosine is an important cell modulator and acts as an endogenous quieting substance via four subtypes of different G-protein-coupled receptors (GPCRs), termed $A_{1}$, $A_{2 A}, A_{2 B}$ and $A_{3}$ receptors $[27,28]$. The $A_{3} R$ is a promising target for molecular imaging, since it is involved in many of the body's cytoprotective functions and changes of the expression leads to a variety of pathologies, especially neurological and affective disorders, cardiac diseases, oncological diseases and inflammation processes [29-31]. In this context, the well-known and high affinity $\mathrm{A}_{3} \mathrm{R}$ agonist, $\left[{ }^{125} \mathrm{I}\right]-4$-aminobenzyl-5'-N-methylcarboxamideoadenosine ([$\left.\left.{ }^{125} \mathrm{I}\right]-\mathrm{AB}-\mathrm{MECA}\right)$ was used to serve as radiolabelled reference compound for both experimental approaches $[32,33]$. Commercially available $\mathrm{A}_{3} \mathrm{R}$ antagonists, 1,4-dihydro-2-methyl-6-phenyl-4-(phenylethynyl)-3,5-pyridinedicarboxylic acid, 3-ethyl 5-(phenylmethyl) ester (MRS1191) and 2,3-ethyl-4,5-dipropyl-6-phenylpyridine-3-thiocarboxylate-5-carboxylate (MRS1523) were used as non-labelled model compounds for the verification of the competitive real-time cell-binding assay [34-36]. In addition, six different in-house synthesized $\mathrm{A}_{3} \mathrm{R}$ antagonists [37-39] were screened in competitive real-time cellbinding studies in order to illustrate the feasibility of the used method. To avoid potential errors and confounding factors due to the physicochemical properties of the used compounds, commercially available and in-house synthesized $A_{3} R$ antagonists were subjected to lipophilicity measurements to determine the logarithm of the octanol-water partition coefficient.

\section{Methods}

\section{Cell culture and petri dish preparation}

Cell-binding studies were conducted on adherent Chinese hamster ovary cells (CHO-K1) and $\mathrm{CHO}-\mathrm{K} 1$ cells stably expressing the human adenosine $\mathrm{A}_{3}$ receptor $\left(\mathrm{CHO}-\mathrm{K} 1-\mathrm{hA} \mathrm{A}_{3} \mathrm{R}\right)$. Both cell lines were a generous gift from Professor Karl-Norbert Klotz (University of Würzburg, Germany) [40]. CHO-K1 and CHO-K1-hA ${ }_{3} \mathrm{R}$ cells were cultured in Ham's F-12 medium (Gibco ${ }^{\circ}$ Life Technologies) containing $1 \%$ penicillin-streptomycin-glutamine (PSG), $10 \%$ fetal bovine serum (FBS) and $300 \mu \mathrm{g} / \mathrm{mL}$ Geneticin (G-418) and incubated in a humidified $5 \% \mathrm{CO}_{2}$ atmosphere at $37^{\circ} \mathrm{C}$. Cells were grown up to $70 \%$ confluence in dedicated tissue culture flask $\left(175 \mathrm{~cm}^{3}\right.$, CELLSTAR $^{\circ}$, Greiner Bio-One) and subcultured latest after 2 days to assure proper cell density, growth and differentiation. The splitting process was induced by washing the cells with $5 \mathrm{~mL}$ Dulbecco's phosphate-buffered saline (DPBS) for $10 \mathrm{~s}$ followed by the incubation with $5 \mathrm{~mL}$ Trypsin-EDTA for $5 \mathrm{~min}$. Subsequently, the cells were resuspended in 10-mL cell culture medium, transferred to a $50-\mathrm{mL}$ conical centrifugation tube (Greiner Bio-One) and centrifuged at $200 \mathrm{~g}$ (1000 rpm) for $5 \mathrm{~min}$. The cell pellet was diluted with $1-\mathrm{mL}$ medium and spread into a new cell culture flask containing 20 mL Ham's F-12 medium with additives.

Three days prior to a binding experiment with LigandTracer ${ }^{\circ}$, petri dishes with approximately $10^{6}$ cells were prepared (Fig. 1). On the first day, the cells were seeded as a monolayer on a local part on the bottom of a tilted cell culture dish $\left(100 \mathrm{~mm} \times 20 \mathrm{~mm}\right.$, CELLSTAR $^{\circ}$, Greiner Bio-One) and incubated with 2-mL medium for $24 \mathrm{~h}$ in order to avoid cell migration. On the consecutive day, the old medium was discarded and the petri dish was preserved in a horizontal position with $10-\mathrm{mL}$ medium for additional $24 \mathrm{~h}$. On the third day, the binding experiment was performed, with fresh medium (3 mL Ham's F-12, serum free).

\section{Radioligands and chemical compounds}

The radioionated no-carrier-added (n.c.a.) $\mathrm{A}_{3} \mathrm{R}$ agonist $\left[{ }^{125} \mathrm{I}\right]$-4-aminobenzyl-5' $-\mathrm{N}$-methylcarboxamideoadenosine $\left(\left[{ }^{125} \mathrm{I}\right]-\mathrm{AB}-\mathrm{MECA}\right)$ was purchased from PerkinElmer ${ }^{\circ}$ (PerkinElmer, Inc., Waltham, USA). $\left[{ }^{125} \mathrm{I}\right]-\mathrm{AB}-\mathrm{MECA}$ was described to reveal high affinity $\left(K_{d}=0.59 \mathrm{nM}\right)$ towards the $\mathrm{A}_{3} \mathrm{R}$ and used to serve as radiolabelled reference compound with high specific activity $\left(81.4 \mathrm{TBq} \mathrm{mmol}^{-1}\right)$ for both experimental approaches [32, 33].

$\mathrm{A}_{3} \mathrm{R}$ antagonists, MRS1191 and MRS1523 were purchased from Sigma-Aldrich (Sigma-Aldrich St. Louis, MO, USA). The pentasubstituted pyridine derivatives 5-(2-fluoroethyl)2,4-diethyl-3-(ethylsulfanylcarbonyl)-6phenylpyridine-5-carboxylate (FE@SUPPY), 5-ethyl 2,4-diethyl-3-((2-fluoroethyl)sulfanylcarbonyl)-6-phenylpyridine-5-carboxylate (FE@SUPPY:2), 4,6-diethyl-5-[(ethylsulfanyl)carbonyl]-2-phenylpyridine-3-carboxylic acid (DFE@SUPPY), methyl 4,6-diethyl-5-\{[(2-fluoroethyl)sulfanyl]carbonyl\}-2-phenylpyridine-3-carboxylate (FEMe@ SUPPY:2), 2-fluoroethyl 4,6-diethyl-5-\{[(2-fluoroethyl)sulfanyl] carbonyl\}-2-phenylpyridine-3-carboxylate ((FE) ${ }^{2} @$ SUPPY) and methyl 4,6-diethyl-5-[(methylsulfanyl)carbonyl]-2-phenylpyridine-3-carboxylate ((Me $\left.)^{2} @ S U P P Y\right)$ were synthesized in our department as described previously [37-39]. All other chemicals were of analytical grade and purchased from commercial sources.

\section{Measurements of the logarithm of the octanol-water partition coefficient}

The logarithm of the octanol-water partition coefficient of the $\mathrm{A}_{3} \mathrm{R}$ antagonists were determined at $\mathrm{pH} 7.4$ by high-performance liquid chromatography (HPLC)-based assay ( $\mathrm{HPLC} \log \mathrm{D}^{7.4}$ ) modified from Donovan and Pescatore [41]. Briefly, a mixture of two internal standards (toluene and triphenylene) with known $\log \mathrm{D}$ values and defined retention times $\left(k^{\prime}\right)$ have been used. $\mathrm{A}_{3} \mathrm{R}$ antagonists were dissolved in methanol and injected onto a short polymeric ODP-50 column $(20 \times 4.0 \mathrm{~mm}$, $5 \mu \mathrm{m}$ pore size, Supelco, Bellefonte, PA, USA). A linear 


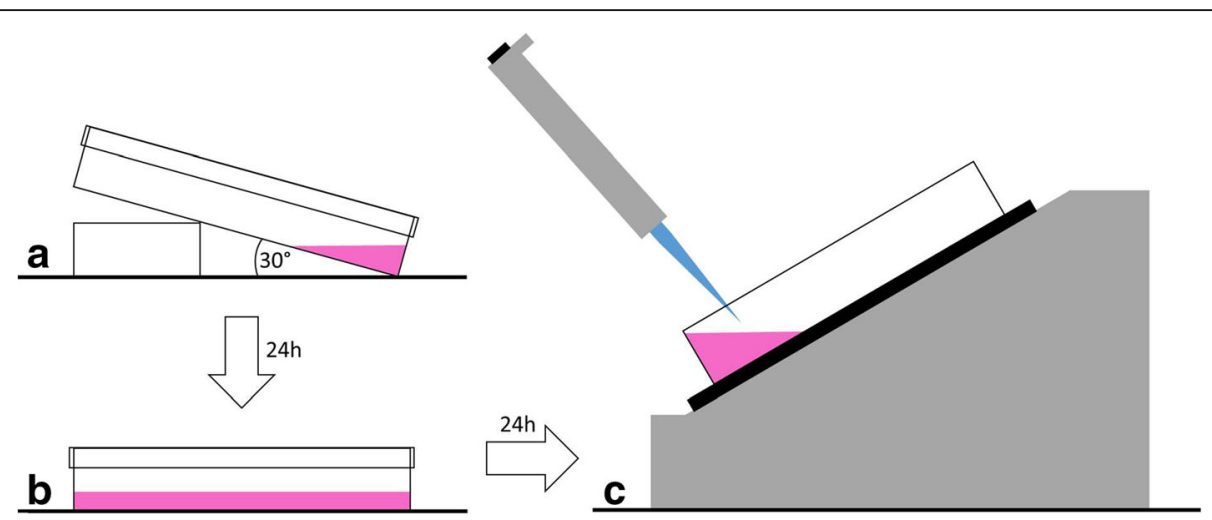

Fig. 1 Schematic illustration of the petri dish preparation. $10^{6} \mathrm{CHO}-\mathrm{K} 1-\mathrm{hA} \mathrm{A}_{3} \mathrm{R}$ cells were seeded on a local part a tilted petri dish and incubated in $2 \mathrm{~mL}$ of medium for $24 \mathrm{~h}$ (a). On the consecutive day, the petri dish was preserved in a horizontal position and the cells were cultured with $10 \mathrm{~mL}$ of fresh medium for additional $24 \mathrm{~h} \mathrm{(b)}$. On the third day, the petri dish was subjected to the binding experiment and the cells were provided with $3 \mathrm{~mL}$ of medium without additives (c)

gradient from $10 \%$ methanol/90\% phosphate buffer (25 mM, pH 7.4) to $100 \%$ methanol within $9.4 \mathrm{~min}$ at a flow rate of $1.5 \mathrm{~mL} / \mathrm{min}$ were applied. Measurement and detection of the three retention times of toluene, triphenylene and $A_{3} R$ antagonists were performed at 260 and $285 \mathrm{~nm}$. Between consecutive HPLC runs, $5 \mathrm{~min}$ for reequilibration of the HPLC column were allowed. The $\log \mathrm{D}$ values of the dedicated compounds were determined using the known $\log \mathrm{D}$ values of triphenylene and toluene and the retention time of triphenylene, toluene and the unknown compounds according to the following formula:

$$
\begin{aligned}
& \log P_{\text {Unknown }} \\
& =\frac{\left(\log P_{\text {tol }}-\log P_{\text {triph }}\right) * t_{\text {Unknown }}+t_{\text {tol }} * \log P_{\text {triph }}-t_{\text {triph }} * \log P_{\text {tol }}}{t_{\text {tol }}-t_{\text {triph }}}
\end{aligned}
$$

where "log $P_{\text {Unknown }}$ " is the $\log \mathrm{D}$ value of the test compound and " $t_{\text {Unknown }}$ " the corresponding measured retention time of the dedicated substance. The $\log \mathrm{D}$ values for the internal standards are abbreviated as "log $P_{\text {tol }}$ " (toluene) and "log $P_{\text {triph" }}$ " (triphenylene), respectively. Measured retention times are indicated as " $t_{\text {tol }}$ " for toluene and " $t_{\text {triph }}$ " for triphenylene.

\section{Kinetic real-time cell-binding studies}

The assay protocol comprised repeated measurements of three points of the dedicated area in which the cells were seeded (cell pole) and three points of the opposing cell-free area (reference pole) of the petri dish as shown in Fig. 2a. Target distribution and cell attachment of the $\mathrm{CHO}-\mathrm{K} 1-\mathrm{hA} \mathrm{A}_{3} \mathrm{R}$ cells were monitored continuously during the whole course of the binding experiment in the perimeter trace (Fig. 2b). Raw signal levels from consecutive measurements $(n=8)$ of a representative experiment after binding equilibrium of $0.7 \mathrm{nM}\left[{ }^{125} \mathrm{I}\right]$ AB-MECA were clearly distinguishable and determined to be $39.51 \pm 0.50,43.82 \pm 0.76$ and $38.69 \pm 0.52$ for the cell pole and $8.55 \pm 0.29,7.41 \pm 0.22$ and $10.74 \pm 0.52$ for the reference pole, respectively, which is outlined in Fig. 2b. The corresponding binding trace of the radioligand was calculated as the difference between the averaged values of the cell pole and the reference pole yielding in a stable background-corrected signal. Kinetic real-time cell-binding studies were conducted on $\mathrm{CHO}$ K1-hA ${ }_{3} \mathrm{R}$ cells with $\left[{ }^{125} \mathrm{I}\right]-\mathrm{AB}-\mathrm{MECA}$ at ambient temperature with LigandTracer ${ }^{\circ}$ Grey. Repeated measurements of the cell pole and the reference pole of the dedicated petri dishes were performed as shown in Fig. 2a. The experiments were started with baseline measurements $10-15$ min prior radioligand incubation. Binding of $\left[{ }^{125} \mathrm{I}\right]-\mathrm{AB}-\mathrm{MECA}$ to the seeded cells was realized by adding different concentrations $(0.05-5 \mathrm{nM})$ to fully cover the concentration span needed for proper affinity estimation. Each dedicated concentration was incubated separately in a single petri dish, and the observed rate constants of the association reaction $\left(\mathrm{k}_{\mathrm{obs}}\right)$ were monitored in real-time until binding equilibrium. Unspecific uptake of the radioligand on the cell surface was confirmed with native $\mathrm{CHO}-\mathrm{K} 1$ cells. As mentioned previously, the perimeter trace of the LigandTracer ${ }^{\circ}$ was used to assure cell viability and attachment.

\section{Competitive real-time cell-binding studies}

The measurements were made according to the assay protocol as previously described above. Competitive real-time cell-binding studies were performed on $\mathrm{CHO}$ $\mathrm{K} 1$ (negative control) and $\mathrm{CHO}-\mathrm{K} 1-\mathrm{hA} \mathrm{A}_{3} \mathrm{R}$ cells in presence of $0.7 \mathrm{nM}\left[{ }^{125} \mathrm{I}\right]-\mathrm{AB}-\mathrm{MECA}$ at ambient temperature with LigandTracer ${ }^{\circ}$ Grey (Ridgeview Instruments $A B$, Uppsala, Sweden). The experiments were initiated with a 

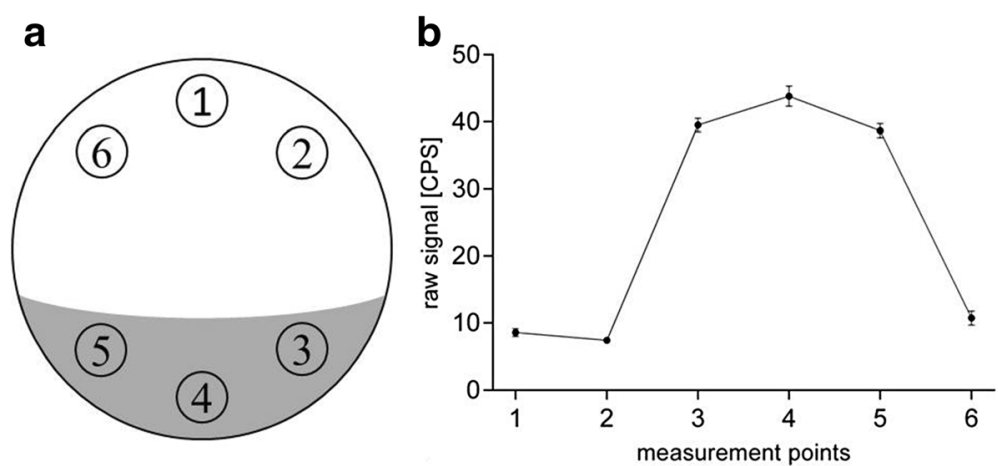

Fig. 2 Representation of the measurement protocol. Real-time binding data of both experimental approaches were acquired according to repeated measurements of six dedicated reading points on a rotating petri dish (a). Measured points 1, 2 and 6 were located in the cell-free area (reference pole), whereas 3, 4 and 5 were set on the area in which the cells were seeded (cell pole). Data from each reading point were acquired over $4 \mathrm{~s}$ with a delay of $2 \mathrm{~s}$ between successive measurements. The corresponding radioactive signal with respect to the dedicated measurement point was monitored continuously in the perimeter trace $(\mathbf{b})$. Representative graph from one experiment. Data are shown as mean \pm SEM from eight consecutive measurements at binding equilibrium. If not visible, error bars are within the margin of the symbols

baseline measurement (10-15 min). Subsequent binding association of $\left[{ }^{125} \mathrm{I}\right]-\mathrm{AB}-\mathrm{MECA}$ was introduced and continuously observed until binding equilibrium $(60-$ $90 \mathrm{~min})$. Inhibition of the radioligand was performed by adding different concentration series (1-500 nM) of unlabelled compounds $\left(\mathrm{A}_{3} \mathrm{R}\right.$ antagonists) each after visual binding equilibrium. At least four different concentrations of competitor, spanning three orders of magnitude adjusted appropriately for the $\mathrm{IC}_{50}$ of each compound, were used. Unspecific binding was determined in the presence of a high concentration $(0.5-100 \mu \mathrm{M})$ of the non-labelled competitor substance. The observed association phase of the radioligand and the dissociation phase of each consecutive concentration of the competitor substance were monitored in real-time until visual binding equilibrium was reached. All non-labelled compounds were initially dissolved in DMSO and diluted with deionized water to the final concentration, where the amount of DMSO never exceeded 5\%. Cytophysiological conditions and cell attachment were examined continuously during the whole course of the experiment with the perimeter trace of the LigandTracer ${ }^{\circ}$ software (version 1.0.1).

\section{Data analysis and statistical procedures}

Raw data from the LigandTracer ${ }^{\circ}$ measurements were analysed in GraphPad Prism 6.0 (GraphPad Software, Inc., San Diego, CA). Experiments were conducted at least as a triplicate with different batches of radioligand and biological target material to avoid systematic bias and to assure statistical certainty. In competitive real-time cellbinding studies binding association of $\left[{ }^{125} \mathrm{I}\right]-\mathrm{AB}-\mathrm{MECA}$ was transformed to start at time point zero. Transformed data was analysed using "one-phase association" curve fitting algorithm as outlined in the following equation:

$$
Y=Y_{0}+\left(\text { Plateau }-Y_{0}\right) *\left(1-e^{-k * x}\right)
$$

where " $x$ " is a given time and " $Y$ " corresponds to the amount of radioligand binding for a dedicated time point. " $Y_{0}$ " is the initial value of " $Y$ " at the beginning of radioligand incubation and "plateau" indicates the maximum amount of the bound radioligand after equilibrium. " $k$ " is the rate constant expressed in reciprocal units of " $x$ ".

Observed dissociation phases of $\left.{ }^{125} \mathrm{I}\right]$-AB-MECA governed by different concentrations of cold competitor were transformed to start at time point zero. Transformed data were analysed by using "dissociation-onephase exponential decay" curve fit as follows:

$$
Y=\left(Y_{0}-\mathrm{NS}\right) * e^{-k * x}+\mathrm{NS}
$$

where " $x$ " is a given time and " $Y$ " corresponds to the amount of bound radioligand for a dedicated time point. " $Y_{0}$ " is the initial value of " $Y$ " at the beginning of each dissociation phase and "NS" indicates the steady state of radioligand binding in the presence of dedicated cold competitor after infinite time. " $k$ " is the rate constant expressed in reciprocal units of " $x$ ".

Equilibrium binding data determined in Eqs. (2) and (3) served as input parameters for the calculation of the $\mathrm{IC}_{50}$ using "log(inhibitor) vs. response-variable slope (four parameters)" nonlinear regression algorithm as described below:

$$
Y=\text { Bottom }+(\text { Top-Bottom }) /\left(1+10^{\left(\left(\log \left(\mathrm{IC}_{50}\right)-C\right) * \text { Hilllslope }\right)}\right)
$$

where " $C$ " is the logarithm of the competitor concentration and " $Y$ " reflects the dedicated amount of bound radioligand at equilibrium obtained from Eq. (3). "Top" indicates the maximum amount of radioligand binding 
(without any competitor) whereas the corresponding value is derived from Eq. (2). "Bottom" expresses the amount of unspecific radioligand binding in presence of a very high concentration of competitor. The dedicated value is determined by Eq. (3) and corresponds to the "NS" value of the last inhibitor concentration. The "HillSlope" reflects the slope factor, which indicates the steepness of the resulting inhibition curve. $" \log \left(\mathrm{IC}_{50}\right)$ " represents the logarithm of the competitor concentration where $50 \%$ of the initial amount of bound radioligand is inhibited. The resulting $\mathrm{IC}_{50}$ was converted into the $K_{i}$ using Cheng-Prusoff Eq. (3).

Data of the observed association phases determined in kinetic real-time cell-binding studies were transformed to start at time point zero. Transformed data were grouped together and globally fitted by using "association kinetics-two or more conc. of hot" to derive a single best-fit estimate for $k_{\text {on }}$ and $k_{\text {off }}$ as described as follows:

$$
Y=Y_{\max } * 1-e^{-k_{\mathrm{ob}} * x}
$$

where " $x$ " is a given time and " $Y$ " reflects the amount of bound radioligand for a dedicated time point. " $Y_{\max }$ " corresponds to the maximum amount of bound radioligand after equilibrium and " $k_{\mathrm{ob}}$ " expresses the observed rate constant of the association reaction.

The observed rate constant of the association reaction is a function of the dedicated radioligand concentration, the association rate constant and the dissociation rate constant, which is described as follows:

$$
k_{\mathrm{ob}}=k_{\mathrm{on}} * L+k_{\mathrm{off}}
$$

where " $k_{\mathrm{ob}}$ " is the observed rate constant of the association reaction, " $k_{\mathrm{on}}$ " represents the association rate constant, " $L$ " reflects the radioligand concentration and " $k_{\text {off }}$ " indicates the dissociation rate constant. Considering Eqs. (5) and (6), best fit estimations for $k_{\text {on }}$ and $k_{\text {off }}$ can be calculated by using multiple radioligand concentrations. The resulting rate constants were used to obtain the $K_{d}$ as the ratio of $k_{\text {off }} / k_{\text {on }}$. An estimation of the target concentration of each single petri dish was derived by using the following equation:

$$
Y_{\max }=\left(L /\left(L+K_{d}\right)\right) * B_{\max }
$$

where " $Y_{\max }$ " is the maximum amount of bound radioligand after equilibrium and " $B_{\max }$ " reflects the maximum amount of target receptors. " $L$ " corresponds to the radioligand concentration and " $K_{d}$ " indicates the affinity of dedicated radioligand.

Unless mentioned otherwise, all experimental data are expressed as mean \pm SEM as determined by GraphPad Prism 6 (GraphPad Software, Inc., San Diego, CA) software analysis. Descriptive statistical measures were used to confirm the goodness of the nonlinear regression models. Differences among groups were proved using two-tailed, unpaired Student's $t$ test with Welch's correction. Multiple comparisons testing was performed using either ordinary one-way ANOVA with Tukey's correction or ordinary two-way ANOVA with Sidak's correction. Values of $P<0.05$ were considered as statistically significant.

\section{Results}

Verification of the target distribution and $h A_{3} R$ expression

Kinetic studies with both $\mathrm{CHO}-\mathrm{K} 1$ and $\mathrm{CHO}-\mathrm{K} 1-\mathrm{hA} \mathrm{A}_{3} \mathrm{R}$ cells were conducted in a reliable and reproducible manner with high spatial and temporal resolution to verify specific radiotracer uptake on the dedicated target receptor (Fig. 3). Differences of the binding association of $\left[{ }^{125} \mathrm{I}\right]-\mathrm{AB}-\mathrm{MECA}$ between $\mathrm{CHO}-\mathrm{K} 1$ and $\mathrm{CHO}-\mathrm{K} 1-\mathrm{hA} 3 \mathrm{R}$ from three independent experiments were proved to be statistically significant $(P<0.0001)$ using two-way repeated measures ANOVA with Sidak's multiple comparisons test.

\section{Measurements of the logarithm of the octanol-water partition coefficient}

Lipophilicity measurements were performed to evaluate the ${ }_{\text {HPLC }} \log \mathrm{D}^{7.4}$ of the $\mathrm{A}_{3} \mathrm{R}$ antagonists, used in the competitive real-time cell-binding studies. Data were determined with high reliability and reproducibility and found to show considerable differences among the dedicated compounds ranging from $0.97 \pm 0.37$ up to $4.85 \pm 0.01$.

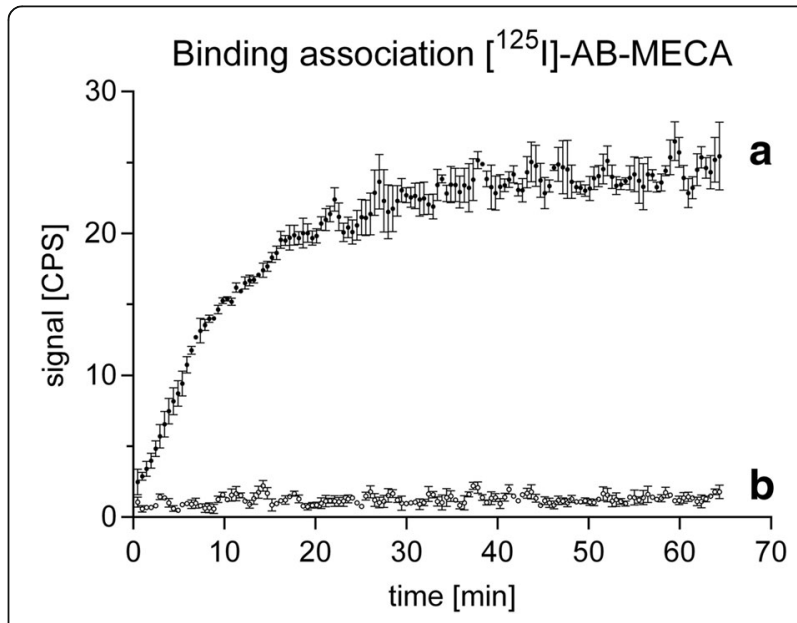

Fig. 3 Representative association kinetics of [125I]-AB-MECA. Binding association of $0.7 \mathrm{nM}\left[{ }^{[25}\right]$-AB-MECA at ambient temperature to CHO-K1$\mathrm{h} \mathrm{A}_{3} \mathrm{R}$ cells $(\mathbf{a})$ and to $\mathrm{CHO}-\mathrm{K} 1$ cells, without the dedicated target receptor (b). Differences were proved to be statistically significant $(P<0.0001)$ using two-way repeated measures ANOVA with Sidak's multiple comparisons test. Data are expressed as mean \pm SEM from three independent experiments. If not visible, error bars are within the margin of the symbols 
Table 1 Estimates of the $K_{i}$ values determined in competitive real-time cell-binding experiments

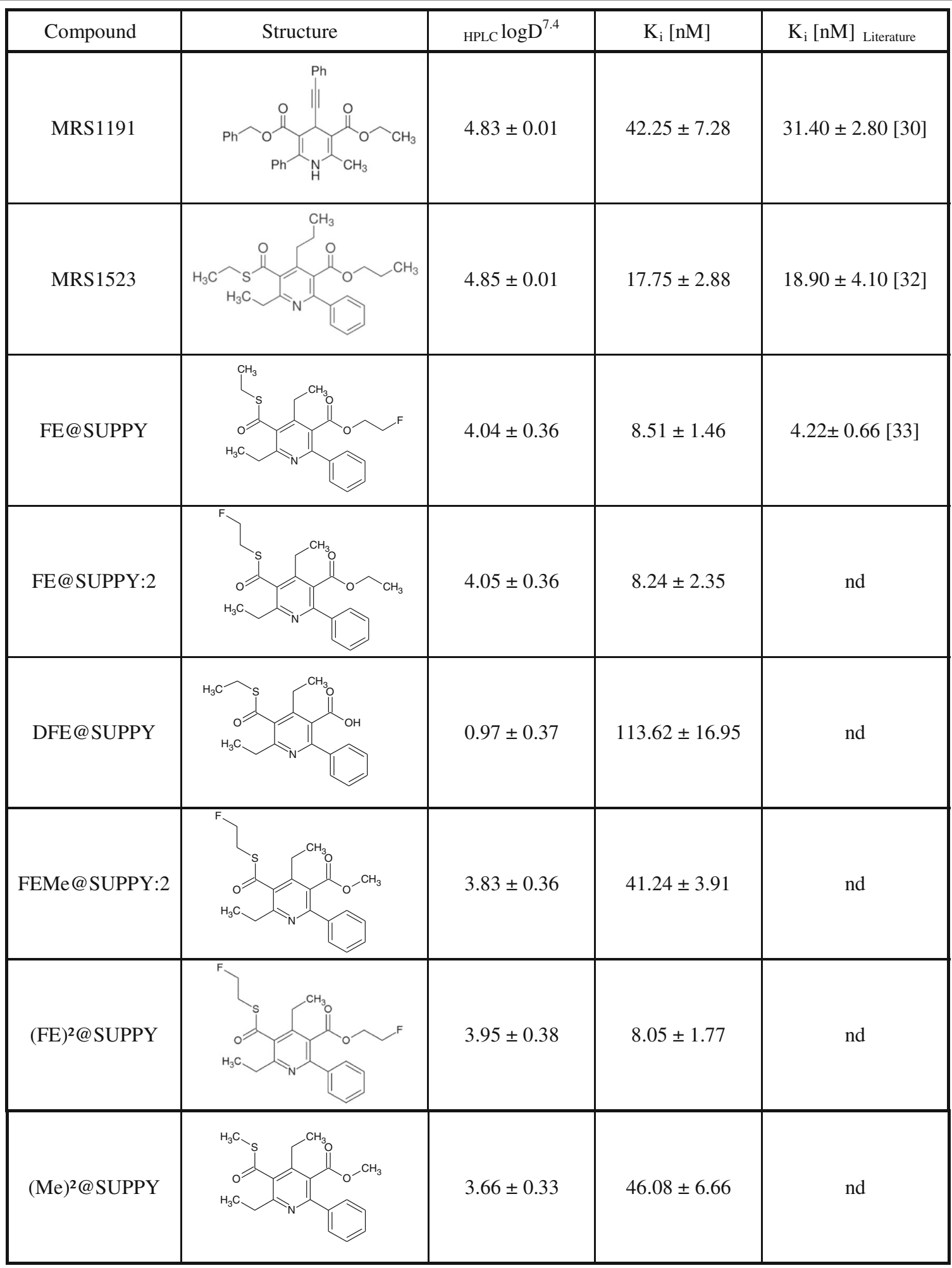

Displacement of specific [ $\left.{ }^{125} \mathrm{I}\right]-\mathrm{AB}-\mathrm{MECA}$ binding on $\mathrm{CHO}-\mathrm{K} 1-\mathrm{hA}{ }_{3} \mathrm{R}$ cells at ambient temperature in presence of different $\mathrm{A}_{3} \mathrm{R}$ antagonists with corresponding HPLClog $D^{7.4}$ parameters. Reported affinity values were determined with traditional binding assays using membranes from human $A_{3} R$-transfected HEK-293 cells. Data in the table are expressed as mean \pm SEM from three independent experiments 
A detailed summary of the corresponding HPLC $\log \mathrm{D}^{7.4}$ values is shown in Table 1. Data are expressed as mean \pm SEM of three independent experiments, each performed in triplicate.

\section{Competitive real-time cell-binding studies}

An illustration of a representative competitive real-time cell-binding experiment with $\left[{ }^{125} \mathrm{I}\right]-\mathrm{AB}-\mathrm{MECA}$ is shown in Fig. 4. Binding kinetics of radioligand association and
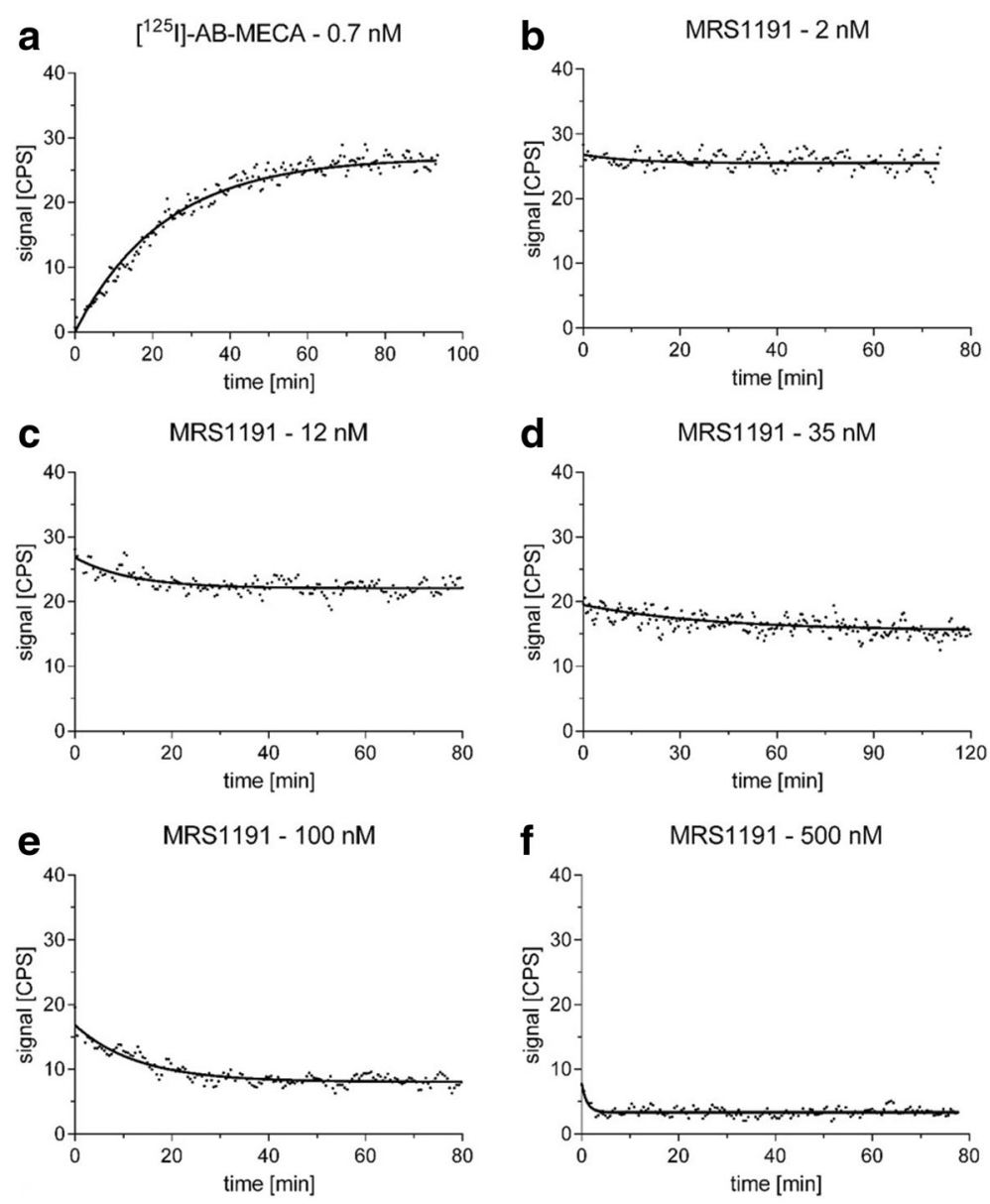

g Competitive binding curve $\left[{ }^{125}\right]$-AB-MECA with MRS1191

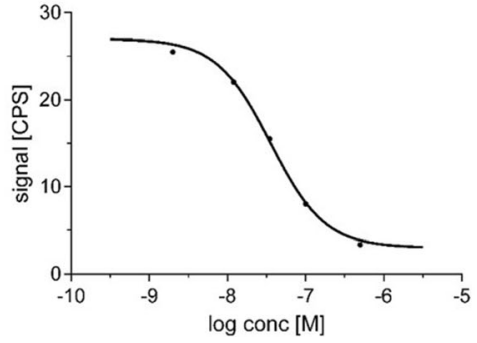

Fig. 4 Schematic representation of the competitive real-time cell-binding experiment. Association kinetics of 0.7 nM [25] ]-AB-MECA at ambient temperature to $\mathrm{CHO}-\mathrm{K} 1-\mathrm{hA}{ }_{3} \mathrm{R}$ (a). Association data were fitted in GraphPad Prism 6.0 using "one-phase association". The value corresponding to the amount of bound radioligand at equilibrium was obtained using Eq. (2). Consecutive concentration-dependent dissociation kinetics of $0.7 \mathrm{nM}$ $\left[{ }^{125}\right.$ ] ]-AB-MECA in the presence of $2 \mathrm{nM}(\mathbf{b}), 12 \mathrm{nM}(\mathbf{c}), 35 \mathrm{nM}(\mathbf{d}), 100 \mathrm{nM}(\mathbf{e})$ and $500 \mathrm{nM}(\mathbf{f})$ of the $\mathrm{A}_{3} R$ antagonist MRS1191, respectively. Dissociation data were fitted using "dissociation - one-phase exponential decay". Values of the remaining radioligand binding after equilibrium were obtained from Eq. (3). The competitive binding curve of [125I]-AB-MECA with MRS1191 (g) was created by means of combination of the equilibrium binding data obtained in Eqs. (2) and (3). Data were fitted using "log(inhibitor) vs. response-variable slope (four parameters)" nonlinear regression algorithm and corresponding $I C_{50}$ values were obtained from Eq. (4). As different concentrations of competitor were used for each individual experiment, data in the graphs are shown from one representative experiment 
dissociation were obtained with high precision. As a result, the applied curve fitting algorithms were found to be highly accurate and revealed values for the coefficient of determination of $0.9503 \pm 0.018$ (association phases) and $0.8136 \pm 0.087$ (dissociation phases), respectively. Equilibrium binding data obtained from Eqs. (2) and (3) were proved to serve as stable input parameters for the generation of the competitive binding curve and the associated determination of the $\mathrm{IC}_{50}$. Displacement of specific $\left[{ }^{125} \mathrm{I}\right]$-AB-MECA binding in the presence of different $\mathrm{A}_{3} \mathrm{R}$ antagonists revealed estimates for the $K_{i}$ values as detailed in Table 1 . Results from our experiments demonstrate that the inhibitory constants were varied with respect to modifications on the leaving groups of the pentasubstituted pyridines, whereas a high preservation of the chemical structure among compounds were proved to reveal in similar $K_{i}$ values. Taking into account the lipophilicity of the tested $\mathrm{A}_{3} \mathrm{R}$ antagonists, no influences on the experimental performance and the resulting affinity were observed. Nevertheless, a slight trend was shown, which a decrease of the $\log \mathrm{D}$ value is associated with an increasing $K_{i}$. Differences of the inhibitory constants of MRS1191, MRS1523 and FE@SUPPY obtained from our competitive realtime cell-binding experiments and those previously reported with membranes from human $\mathrm{A}_{3} \mathrm{R}$ transfected HEK-293 cells in traditional binding assays $[30,32,33]$ were found to be statistically not significant $(P>0.05)$ using ordinary two-way ANOVA with Sidak's correction (Fig. 5).

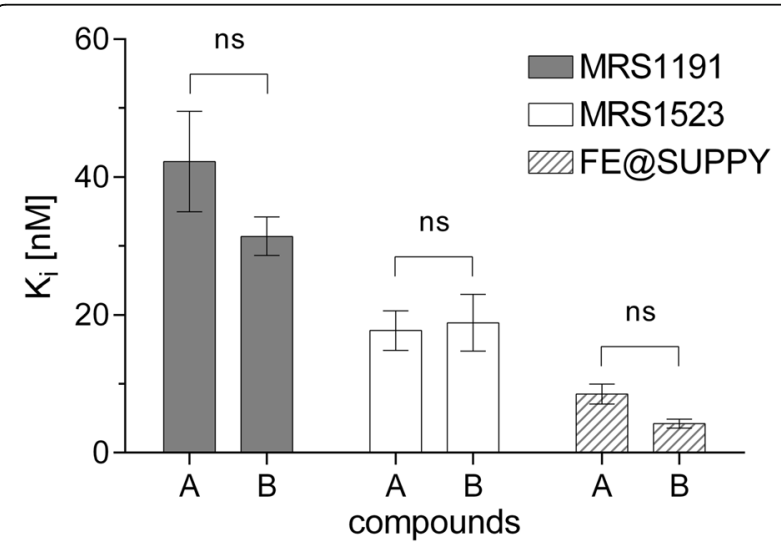

Fig. 5 Comparison of obtained and reported $K_{i}$ values. Inhibitory constants of the $A_{3} R$ antagonists MRS1191, MRS1523 and FE@SUPPY, respectively, were obtained from competitive real-time cell-binding studies at ambient temperature with $0.7 \mathrm{nM}\left[{ }^{125} \mathrm{l}\right]-\mathrm{AB}-\mathrm{MECA}$ on $\mathrm{CHO}-$ $\mathrm{K} 1-\mathrm{hA} \mathrm{A}_{3} \mathrm{R}$ cells (group $\mathrm{A}$ ) and compared to the corresponding $K_{i}$ values obtained from traditional binding assays, as previously reported in the literature (group B). Differences for MRS1 191, MRS1523 and FE@SUPPY among groups are statistically not significant ( $n s=P>0.05$ ), using ordinary two-way ANOVA with Sidak's correction. Data in the graph are shown as mean \pm SEM from three independent experiments (see Table 1 for summary of dedicated $K_{i}$ values)

\section{Kinetic real-time cell-binding studies}

Kinetic real-time cell-binding experiments were performed to determine the $K_{d}$ of the radiolabelled $\mathrm{A}_{3} \mathrm{R}$ agonist $\left[{ }^{125} \mathrm{I}\right]-\mathrm{AB}-\mathrm{MECA}$ based on the quantification of the rate constants $k_{\text {on }}$ and $k_{\text {off. }}$ The observed association time-courses of the dedicated radioligand concentrations were obtained with high spatial and temporal resolution (Fig. 6a). Applied curve fitting algorithms were proved to be consistent with the measured data points, and best-fit estimations for $k_{\text {on }}$ and $k_{\text {off }}$ were determined using Eqs. (5) and (6) with high reliability and accuracy (Table 2). To validate these findings, the binding traces of $\left[{ }^{125} \mathrm{I}\right]-\mathrm{AB}-\mathrm{MECA}$ were analysed separately from each other using one-phase association curve fitting algorithm and resulting $k_{\text {obs }}$ values were plotted against the dedicated radioligand concentration (Fig. 6b). Linear regression analysis was found to show high correlation $\left(R^{2}=\right.$ $0.9927)$ and revealed values for $k_{\text {on }}$ of $8.859 \times 10^{7} \pm$ $0.299 \times 10^{7} \mathrm{M}^{-1} \mathrm{~min}^{-1}$ and for $k_{\text {off }}$ of $0.049 \pm 0.006 \mathrm{~min}^{-1}$, which are in good agreement with the rate constants obtained from the global fitting approach. To control confounding factors due to potential variations of the dedicated target protein, an assessment of associated $\mathrm{hA}_{3} \mathrm{R}$ expression levels was obtained using Eq. (7). Corresponding signal values were found to confirm homogenous receptor expression within the whole binding experiment (Fig. 6c). The difference between the $K_{d}$ of [ $\left.{ }^{125} \mathrm{I}\right]-\mathrm{AB}-\mathrm{MECA}$ obtained from our kinetic binding approach and the binding data as previously reported in the literature with traditional saturation binding assays on membranes from human $\mathrm{A}_{3} \mathrm{R}$-transfected HEK-293 cells [29] was proved to be statistically not significant $(P>0.05)$ using two-tailed, unpaired Student's $t$ test with Welch's correction (Fig. 6d). A detailed summary of $k_{\text {on }}, k_{\text {off }}$ and $K_{d}$ values are given in Table 2. Fitting parameters for $k_{\text {on }}$ and $k_{\text {off }}$ were obtained using a set of eight different concentrations of $\left[{ }^{125} \mathrm{I}\right]-\mathrm{AB}-\mathrm{MECA}$ spanning two orders of magnitude needed for proper affinity estimation. Reliability and effectiveness of the experimental approach were proved by comparing the resulting $K_{d}$, determined using the full set of concentrations, with the corresponding $K_{d}$ values, calculated from best-fit estimations for the rate constants using two, three, four, five, six or seven concentrations of the radioligand, respectively. Differences between $K_{d}$ values were determined to be statistically not significant $(P>0.05)$, using ordinary one-way ANOVA with Tukey's multiple comparisons correction (Fig. 7a). Best-fit estimations were found to be less precise when using only a set of two, three or four concentrations of radioligand. An analysis of the differences between averaged $K_{d}$ values revealed that there is a high preservation of the estimated binding affinity, starting from the usage of five radioligand concentrations (Fig. 7b). 
a
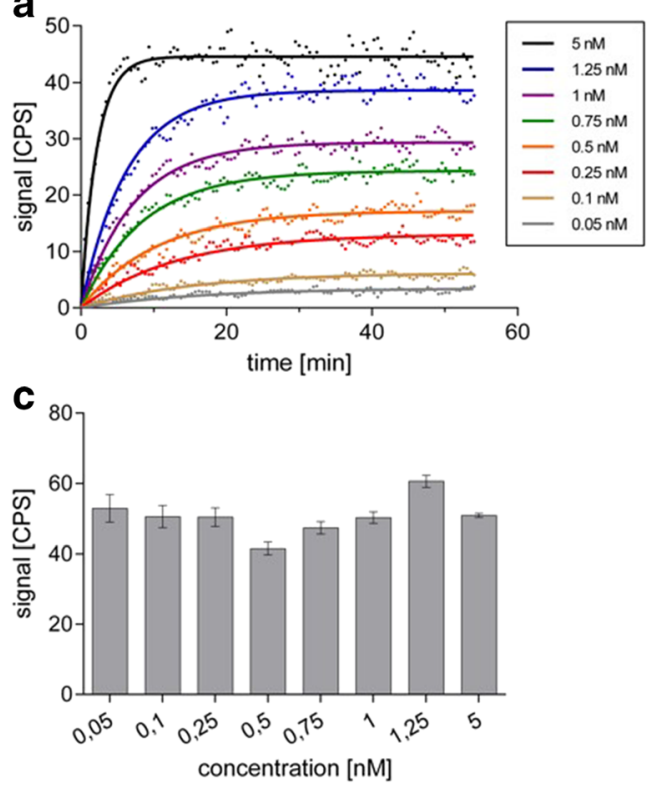

b

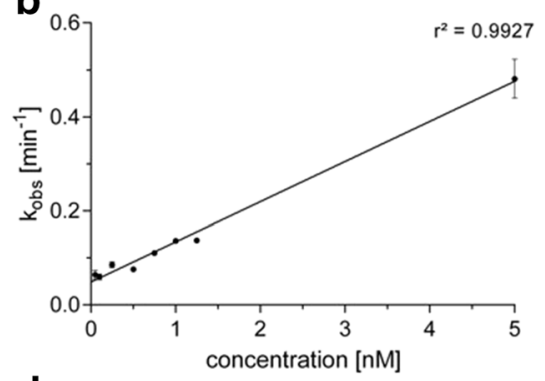

d

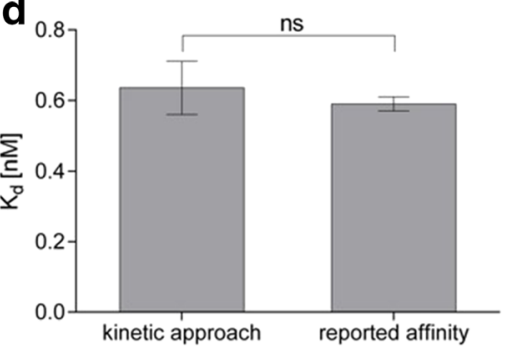

Fig. 6 Graphical representation of the kinetic real-time cell-binding approach. Observed association time-courses of [ ${ }^{125}$ ] $]-A B-M E C A$ to $C^{-H O}-K 1-h A_{3} R$ at several concentrations (0.05-5 nM) spanning the $K_{d}(\mathbf{a})$. Real-time binding data were globally fitted in GraphPad Prism 6.0 using "association kinetics-two or more conc. of hot" (solid lines). Best-fit estimations for $k_{\text {on }}$ and $k_{\text {off }}$ were obtained from Eqs. (5) and (6). Resulting rate constants were used to determine the $K_{d}$ (see Table 2 for summary of dedicated $k_{\text {on, }} k_{\text {off }}$ and $K_{d}$ values). To verify these results, $k_{\text {obs }}$ values were determined using Eq. (2) and plotted against the corresponding concentration of [ [25] ]-AB-MECA (b). Values for $k_{\text {on }}$ and $k_{\text {off }}$ calculated from linear regression analysis are in good agreement with values obtained from the global fit estimation. An estimation of the associated target concentration of each single petri dish was used to confirm homogenous receptor expression within the whole binding experiment (c). Values corresponding to the maximum amount of target receptors were obtained using Eq. (7). The $K_{d}$ of ${ }^{[25}[]$-AB-MECA obtained from the novel kinetic real-time cell-binding studies and from traditional binding assays, as previously reported in the literature (see Table 2 for detailed summary of $K_{d}$ values), was compared using two-tailed, unpaired Student's $t$ test with Welch's correction (d). Differences between the $K_{d}$ values are statistically not significant ( $n s=P>0.05$ ). Data in the graph $(\mathbf{a})$ are shown from one representative experiment. Data in the graphs (b-d) are shown as mean \pm SEM from individual experiments $(n \geq 4)$

\section{Discussion}

Radioligand-binding studies provide excellent quantitative data with high sensitivity, but are time-consuming, laborious and lack the possibility of high spatial and temporal data acquisition [16]. Considering this, the described approaches improve the determination of binding kinetics, resulting in a more time-efficient and comprehensive data acquisition, with high spatial and temporal resolution. Resolving the kinetic mechanisms of biomolecular interactions has become more and more

Table 2 Best-fit estimations of the rate constants and the resulting $K_{d}$ values in kinetic real-time cell-binding experiments

\begin{tabular}{|c|c|c|c|c|c|}
\hline Fitting approach & $k_{\text {on }}\left[\mathrm{M}^{-1} \mathrm{~min}^{-1}\right]$ & $k_{\text {off }}\left[\mathrm{min}^{-1}\right]$ & $K_{d}[\mathrm{nM}]$ & $R^{2}$ & $d f$ \\
\hline 2 concentrations & $8.675 \times 10^{7} \pm 0.414 \times 10^{7}$ & $0.077 \pm 0.008$ & $0.887 \pm 0.121$ & 0.992 & 216 \\
\hline 3 concentrations & $9.262 \times 10^{7} \pm 0.835 \times 10^{7}$ & $0.049 \pm 0.007$ & $0.528 \pm 0.118$ & 0.991 & 325 \\
\hline 4 concentrations & $9.243 \times 10^{7} \pm 0.919 \times 10^{7}$ & $0.051 \pm 0.007$ & $0.556 \pm 0.132$ & 0.988 & 434 \\
\hline 5 concentrations & $8.805 \times 10^{7} \pm 0.289 \times 10^{7}$ & $0.062 \pm 0.003$ & $0.704 \pm 0.054$ & 0.994 & 543 \\
\hline 6 concentrations & $8.788 \times 10^{7} \pm 0.292 \times 10^{7}$ & $0.061 \pm 0.003$ & $0.695 \pm 0.052$ & 0.993 & 652 \\
\hline 7 concentrations & $8.105 \times 10^{7} \pm 0.259 \times 10^{7}$ & $0.055 \pm 0.003$ & $0.683 \pm 0.056$ & 0.993 & 761 \\
\hline 8 concentrations & $8.068 \times 10^{7} \pm 0.260 \times 10^{7}$ & $0.057 \pm 0.003$ & $0.711 \pm 0.056$ & 0.993 & 870 \\
\hline Averaged & $6.645 \times 10^{7} \pm 1.423 \times 10^{7}$ & $0.043 \pm 0.014$ & $0.636 \pm 0.076$ & nd & nd \\
\hline Reported affinity & nd & nd & $0.59 \pm 0.02[29]$ & nd & nd \\
\hline
\end{tabular}

Curve fitting parameters of the association rate constant and the dissociation rate constant of [25I]-AB-MECA on CHO-K1-hA3R cells at ambient temperature. Dedicated $K_{d}$ values were calculated as the ratio of $k_{\mathrm{off}} / k_{\mathrm{on}}$. The table summarizes best-fit estimations and corresponding goodness of fit parameters for a set of different amount of concentrations of [125]]-AB-MECA. The "averaged" value comprises data from three independent experiments. Reported $K_{d}$ was determined with traditional saturation binding assays using membranes from human $A_{3} R$-transfected HEK-293 cells. Data in the table are expressed as mean \pm SEM from individual experiments $(n \geq 4)$ nd not determined 

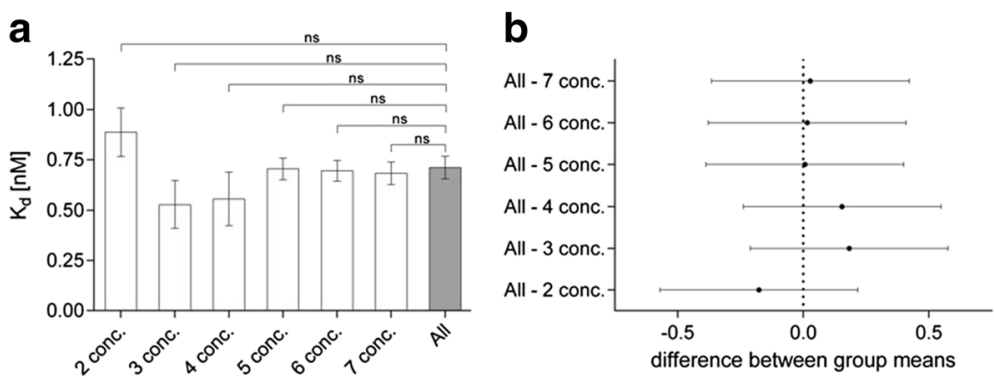

Fig. 7 Verification and performance analysis of kinetic-real time cell-binding studies. Best-fit estimations for $k_{\text {on }}$ and $k_{\text {off }}$ were obtained using Eqs. (5) and (6), as detailed in the methods, and resulting $K_{d}$ were calculated as the ratio of $k_{\text {off }} / k_{\text {on }}$. Fitted rate constants were determined using eight different concentrations $(0.05-5 \mathrm{nM})$ of [ ${ }^{125}\left[\right.$ ]-AB-MECA to fully cover the concentration span needed for proper affinity estimation. The corresponding $K_{d}$ (all) was compared to $K_{d}$ values, calculated from best-fit estimations for the rate constants using two (2 conc.), three (3 conc.), four ( 4 conc.), five (5 conc.), six ( 6 conc.) or seven (7 conc.) concentrations of the radioligand, respectively (a). Differences between the $K_{d}$ values are statistically not significant (ns $=P>0.05$ ), using ordinary one-way ANOVA with Tukey's multiple comparisons correction (see Table 2 for detailed summary of $k_{\text {on, }} k_{\text {off }}$ and $k_{d}$ values). Differences between group means of the dedicated $K_{d r}$ calculated using the full set of concentrations and the $K_{d}$, determined using less concentrations of the radioligand with the corresponding 95\% confidence intervals (b). Data are expressed as mean \pm SEM from individual experiments $(n \geq 4)$

important to improve the performance of binding experiments and to avoid systematic bias and potential errors of obtained data under equilibrium and non-equilibrium conditions [5-7]. This consideration is supported by an increasing amount of studies, which address a shift from traditional approaches to the characterization of binding kinetics [5, 6, 10-16, 22, 23]. In the present study, we successfully designed and established two experimental approaches for the reliable in vitro assessment of binding affinity of both, radiolabelled and non-labelled compounds, based on high-resolution real-time data acquisition of radioligand-receptor binding kinetics. Realized as competitive real-time cell-binding studies, we introduced an accurate method for the visualization and quantification of radioligand dissociation in the presence of different non-labelled competitor concentrations (Fig. 4). Time-resolved quantitative data about the kinetic mechanisms of the competition, provide information beyond the fact that competition occurs, including the relative binding strength or the affinity of the competitor itself. We determined in our competitive real-time cellbinding studies the $K_{i}$ of eight different $\mathrm{A}_{3} \mathrm{R}$ antagonists with high reliability (Table 1 ) and highlighted the suitability of the used method as we confirmed previously published $K_{i}$ values of MRS1191, MRS1523 and FE@SUPPY (Fig. 5). In addition, we demonstrated that the experimental performance was not confounded by variations of the lipophilicity of the tested compounds. In contrast to in vitro binding experiments, in an in vivo setting, the concentration of a dedicated ligand to its target region changes over time and is often influenced by additional factors other than basic biomolecular ligandreceptor interactions. As a consequence, the in vitro measured $K_{d}$ alone provides not sufficient information to characterize complex compound interactions and the potential in vivo effectiveness of small-molecule drugs, but rather the in vitro assessment of radioligandreceptor binding kinetics. Furthermore, we successfully established in kinetic real-time cell-binding studies an experimental design for the effective and reliable quantification of the rate constants $k_{\text {on }}$ and $k_{\text {off }}$ in order to determine the $K_{d}$ of a radiolabelled ligand. Binding experiments with the radiotracer $\left[{ }^{125} \mathrm{I}\right]-\mathrm{AB}-\mathrm{MECA}$, a potent $A_{3} R$ agonist, were found to reveal information of the observed association time courses at various concentrations with high spatial and temporal resolution (Fig. 6). Thus, we determined best-fit estimations for $k_{\text {on }}$ and $k_{\text {off }}$ with high reliability and precision, and the resulting $K_{d}$ was proved to be in good agreement with the affinity previously reported with traditional saturation binding approaches (Table 2; Fig. 6d). In the performance analysis of the experimental approach, we found that, even with a low number of radioligand concentrations, an appropriate estimation of the dedicated $K_{d}$ was possible, making it suitable for cost-efficient screening of potential drug candidates. Moreover, we obtained an estimation of the associated $\mathrm{hA}_{3} \mathrm{R}$ expression levels in order to control confounding factors due to potential variations of the dedicated target protein density $(6 \mathrm{C})$.

\section{Conclusions}

In conclusion, we found that, compared to traditional in vitro binding assays, the time-resolved kinetic approaches described in this paper have several advantages and the practical use is potentially wide. When adding either the radioligand or the competitor, a steady insight into association, retention and dissociation of the radiolabelled ligand is possible during the experiment with high spatial and temporal resolution. This information can be used for the exact determination of binding equilibrium and provides an increased understanding of the occasional complex interplay between radiotracer, ligand 
and the dedicated biological target. Moreover, it has the potential to facilitate the experimental workflow as it enables interactive intervention, minimizes the quantities of the used radiotracer and reduces systematic errors caused by non-equilibrium conditions. In addition, we found that continuously acquired time-resolved kinetic data help to improve the computational postprocessing by providing refined statistical accuracy and advance the formulation of computational methods to analyse biomolecular interactions of ligands with the receptor alone, or in combination. Both kinetic binding approaches comprise tracer administration and subsequent binding to living cells, expressing the dedicated target protein. Therefore, the experiments are more similar to the in vivo physiological conditions and provide important markers of cellular feedback and biological response. Taken all together, the reliable in vitro assessment of time-resolved radioligand-receptor binding kinetics has the potential to provide comprehensive information to the development of radiolabeled probes for molecular imaging.

\section{Abbreviations}

$A_{3} R$ : Adenosine $A 3$ receptor; $B_{\text {Max: }}$ Concentration of specific binding sites; $\mathrm{CHO}-\mathrm{K} 1$ : Chinese hamster ovary cells; $\mathrm{CHO}-\mathrm{K} 1-\mathrm{hA}{ }_{3} \mathrm{R}$ : Chinese Hamster ovary cells stably expressing the human adenosine $A 3$ receptor; FBS: Fetal bovine serum; G-418: Geneticin; GPCR: G-protein-coupled receptor; HPLdogD 7 : : Logarithm of the octanol-water partition coefficient; $\mid \mathrm{C}_{50}$ : Half-maximum inhibitory concentration; $K_{d}$ : Equilibrium dissociation constant; $K_{j}$ : Equilibrium inhibitory constant; $k_{\text {obs: }}$ : Observed rate constant of the association reaction; $k_{\text {off: }}$ Dissociation rate constant; $k_{\text {on }}$ : Association rate constant; PSG: Penicillin-streptomycin-glutamine

\section{Acknowledgements}

This scientific project was performed with the support of the Medical Imaging Cluster of the Medical University of Vienna. We thank Prof. Dr. Karl Norbert Klotz from the University of Wuerzburg for providing us the CHO-K1 and the CHO-K1-hA3R cell lines. Special thanks to Monika Dumanic, MSc for native English editing. We also would like to thank Dr. Daniela Haeusler for initial support.

\section{Funding}

This project was supported by the Austrian Science Fund (FWF P26502-B24) and awarded to M. Mitterhauser.

\section{Authors' contributions}

$M Z$, FP and LN performed the research. MZ and MM designed the research study. $\mathrm{HS}, \mathrm{MH}, \mathrm{WW}$ and $\mathrm{MM}$ contributed to the administrative, technical or material support of the study. MZ and FP analysed the data. MZ, FP, WW and MM wrote the manuscript. All authors read and approved the final manuscript.

\section{Competing interests}

The authors declare that they have no competing interests.

\section{Consent for publication}

Not applicable.

\section{Ethics approval}

Not applicable.

\section{Author details}

'Department of Biomedical Imaging and Image-guided Therapy, Division of Nuclear Medicine, Radiopharmacy and Experimental Nuclear Medicine, Waehringer Guertel 18-20, 1090 Vienna, Austria. Faculty of Engineering, University of Applied Sciences Wiener Neustadt, Wiener Neustadt, Austria. ${ }^{3}$ Department of Inorganic Chemistry, University of Vienna, Vienna, Austria.
${ }^{4}$ Department of Pharmaceutical Chemistry, University of Vienna, Vienna, Austria. ${ }^{5}$ Department of Pharmaceutical Technology and Biopharmaceutics, University of Vienna, Vienna, Austria. ${ }^{6}$ Ludwig Boltzmann Institute for Applied Diagnostics, Vienna, Austria.

Received: 4 November 2016 Accepted: 15 December 2016

Published online: 07 March 2017

\section{References}

1. Clark AJ. Mode of action of drugs on cells. London: Edward Arnold \& Co; 1933.

2. Motulsky HJ, Mahan LC. The kinetics of competitive radioligand binding predicted by the law of mass action. Mol Pharmacol. 1984;25:1-9.

3. Cheng $Y$, Prusoff $W H$. Relationship between the inhibition constant $\left(K_{1}\right)$ and the concentration of inhibitor which causes 50 per cent inhibition $\left(I_{50}\right)$ of an enzymatic reaction. Biochem Pharmacol. 1973;22:3099-108.

4. Hulme EC, Birdsall NJM. Strategy and tactics in receptor-binding studies. In: Hulme EC, editor. Receptor-ligand interactions-a practical approach. Oxford: IRL Press; 1992. p. 63-176.

5. Swinney DC. Biochemical mechanisms of drug action: what does it take for success? Nat Rev Drug Discov. 2004;3:801-8.

6. Swinney DC. The role of binding kinetics in therapeutically useful drug action. Curr Opin Drug Discov Devel. 2009:12:31-9.

7. Hulme EC, Trevethick MA. Ligand binding assays at equilibrium: validation and interpretation. Br J Pharmacol. 2010;161:1219-37.

8. Copeland RA, Pompliano DL, Meek TD. Drug-target residence time and its implication for lead optimization. Nat Rev Drug Discov. 2006;5:730-9.

9. Zhang R, Monsma F. The importance of drug-target residence time. Curr Opin Drug Discov Devel. 2009;12:488-96.

10. Ojima M, Inada Y, Shibouta Y, Wada T, Sanada T, Kubo K, et al. Candesartan (CV-11974) dissociates slowly from the angiotensin AT1 receptor. Eur J Pharmacol. 1997;319:137-46.

11. Anthes JC, Gilchrest H, Richard C, Eckel S, Hesk D, West Jr RE, et al. Biochemical characterization of desloratadine, a potent antagonist of the human histamine H(1) receptor. Eur J Pharmacol. 2002;449:229-37.

12. Dowling MR, Charlton SJ. Quantifying the association and dissociation rates of unlabelled antagonists at the muscarinic $\mathrm{M}_{3}$ receptor. Br J Pharmacol. 2006:148:927-37.

13. Buch I, Giorgino T, De Fabritiis G. Complete reconstruction of an enzymeinhibitor binding process by molecular dynamics simulations. Proc Nat Acad Sci U S A. 2011;108:10184-9.

14. Casarosa P, Kollak I, Kiechle T, Ostermann A, Schnapp A, Kiesling R, et al. Functional and biochemical rationales for the 24-hour-long duration of action of olodaterol. J Pharmacol Exp Ther. 2011:337:600-9.

15. Guo D, Van Dorp EJH, Mulder-Krieger T, Van Veldhoven JPD, Brussee J, IJzerman AP, et al. Dual-point competition association assay: a fast and high-throughput kinetic screening method for assessing ligand-receptor binding kinetics. J Biomol Screen. 2012;18:309-20

16. Emami-Nemini A, Roux T, Leblay M, Bourrier E, Lamarque L, Trinquet $E$, Lohse MJ. Time-resolved fluorescence ligand binding for $G$ protein-coupled receptors. Nat Protoc. 2013:8:1307-20.

17. Heise CE, Sullivan SK, Crowe PD. Scintillation proximity assay as a highthroughput method to identify slowly dissociating nonpeptide ligand binding to the $\mathrm{GnRH}$ receptor. J Biomol Screen. 2007;12:235-9.

18. Packeu A, Wennerberg M, Balendran A, Vauquelin G. Estimation of the dissociation rate of unlabelled ligand-receptor complexes by a 'two-step' competition binding approach. Br J Pharmacol. 2010;161:1311-28.

19. Björke $H$, Andersson $K$. Measuring the affinity of a radioligand with its receptor using a rotating cell dish with in situ reference area. Appl Radiat Isot. 2006;64:32-7.

20. Nilvebrant J, Kuku G, Björkelund H, Nestor M. Selection and in vitro characterization of human CD44v6-binding antibody fragments. Biotechnol Appl Biochem. 2012;59:367-80

21. Xu B, Varasteh Z, Orlova A, Andersson K, Larhammar D, Björkelund H. Detecting ligand interactions with $G$ protein-coupled receptors in real-time on living cells. Biochem Biophys Res Commun. 2013:441:820-4.

22. Barta $\mathrm{P}, \mathrm{Björkelund} \mathrm{H}$, Andersson $\mathrm{K}$. Circumventing the requirement of binding saturation for receptor quantification using interaction kinetic extrapolation. Nucl Med Commun. 2011;3:1-5.

23. Bjorke $\mathrm{H}$, Andersson K. Automated, high-resolution cellular retention and uptake studies in vitro. Appl Radiat Isot. 2006;64:901-5. 
24. Björkelund H, Gedda L, Malmqvist M, Andersson K. Resolving the EGF-EGFR interaction characteristics through a multiple-temperature, multiple-inhibitor, real-time interaction analysis approach. Mol Clin Oncol. 2013;1:343-52.

25. Spiegelberg D, Stenberg J, Haylock AK, Nestor M. A real-time in vitro assay as a potential predictor of in vivo tumor imaging properties. Nucl Med Biol. 2016:43:12-8.

26. Stenberg J, Spiegelberg D, Karlsson H, Nestor M. Choice of labeling and cell line influences interactions between the Fab fragment AbD15179 and its target antigen CD44v6. Nucl Med Biol. 2014;41:140-7.

27. Fredholm BB, IJzerman AP, Jacobson KA, Klotz KN, Linden J. International Union of Pharmacology. XXV. Nomenclature and classification of adenosine receptors. Pharmacol Rev. 2001;53:527-52.

28. Fredholm BB, IJzerman AP, Jacobson KA, Linden J, Müller CE. International Union of Basic and Clinical Pharmacology. LXXXI. Nomenclature and classification of adenosine receptors-an update. Pharmacol Rev. 2011;63:1-34.

29. Liang B, Jacobson KA. A physiological role of the adenosine $A 3$ receptor: sustained cardioprotection. Proc Natl Acad Sci U S A. 1998:95:6995-9.

30. von Lubitz D, Simpson K, Lin R. Right thing at a wrong time? Adenosine A3 receptors and cerebroprotection in stroke. Ann N Y Acad Sci. 2001;939:85-96.

31. Jacobson KA, Gao ZG. Adenosine receptors as therapeutic targets. Nat Rev Drug Discov. 2006;5:247-64.

32. Olah ME, Gallo-Rodriguez C, Jacobson KA, Stiles GL. 125l-4-aminobenzyl-5'$\mathrm{N}$-methylcarboxamidoadenosine, a high affinity radioligand for the rat $\mathrm{A} 3$ adenosine receptor. Mol Pharmacol. 1994;45:978-82.

33. Ji XD, Melman N, Jacobson KA. Interactions of flavonoids and other phytochemicals with adenosine receptors. J Med Chem. 1996:39:781-8.

34. Jiang JL, van Rhee AM, Melman N, Ji XD, Jacobson KA. 6-phenyl-1,4dihydropyridine derivatives as potent and selective $\mathrm{A} 3$ adenosine receptor antagonists. J Med Chem. 1996;39:4667-75.

35. Jacobson KA, Park KS, Jiang JL, Kim YC, Olah ME, Stiles GL, Ji XD. Pharmacological characterization of novel A3 adenosine receptor-selective antagonists. Neuropharmacology. 1997;36:1157-65.

36. Li AH, Moro S, Melman N, Ji XD, Jacobson KA. Structure-activity relationships and molecular modeling of 3,5-diacyl-2,4-dialkylpyridine derivatives as selective A3 adenosine receptor antagonists. J Med Chem. 1998:41:3186-201.

37. Li AH, Moro S, Forsyth N, Melman N, Ji XD, Jacobson KA. Synthesis, CoMFA analysis, and receptor docking of 3,5-diacyl-2,4-dialkylpyridine derivates as selective A3 adenosine receptor antagonists. J Med Chem. 1999;42:706-21.

38. Shanab K, Wadsak W, Mien LK, Mitterhauser M, Holzer W, Polster V, et al. Synthesis of in vivo metabolites of the new adenosine A3 receptor PETradiotracer [18F]FE@SUPPY. Heterocycles. 2008;75:339-56.

39. Haeusler D, Mitterhauser M, Mien LK, Shanab K, Lanzenberger R, Schirmer E, et al. Radiosynthesis of a novel potential adenosine A3 receptor ligand, 5ethyl 2,4-diethyl-3-((2-[18F]fluoroethyl(sulfanylcarbonyl)-6-phenylpyridine-5carboxylate ([18F]FE@SUPPY:2). Radiochem Acta. 2009;97:753-8.

40. Klotz KN, Hessling J, Hegler J, Owman C, Kull B, Fredholm BB, Lohse MJ. Comparative pharmacology of human adenosine receptor subtypes - characterization of stably transfected receptors in $\mathrm{CHO}$ cells. Naunyn Schmiedebergs Arch Pharmacol. 1998;357:1-9.

41. Donovan SF, Pescatore MC. Method for measuring the logarithm of the octanolwater partition coefficient by using short octadecyl-poly(vinyl alcohol) highperformance liquid chromatography columns. J Chromatogr A. 2002;952:47-61.

\section{Submit your manuscript to a SpringerOpen ${ }^{\circ}$ journal and benefit from:}

- Convenient online submission

- Rigorous peer review

- Immediate publication on acceptance

- Open access: articles freely available online

- High visibility within the field

Retaining the copyright to your article 